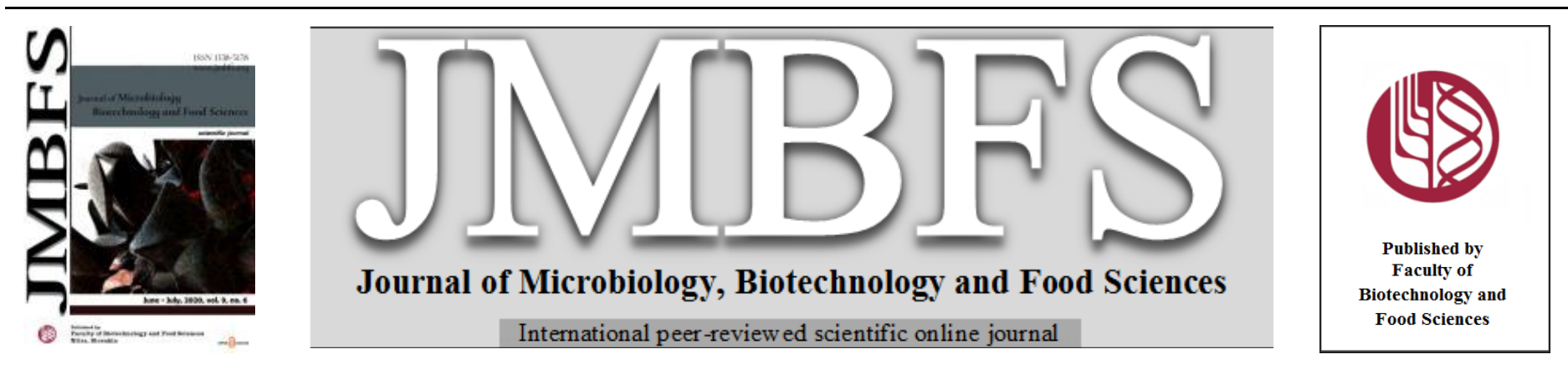

\title{
A BIOPROCESS DEVELOPMENT STUDY OF POLYPHENOL PROFILE, ANTIOXIDANT AND ANTIMICROBIAL ACTIVITIES OF KOMBUCHA ENRICHED WITH Psidium guajava $\mathrm{L}$.
}

\author{
Mona M. Khaleil ${ }^{1,2}$, Sawsan Abd Ellatif ${ }^{* 3}$, Mona H. Soliman ${ }^{4}$, Elsayed S. Abd Elrazik ${ }^{5}$ and Mayada Sh. Fadel ${ }^{3}$ \\ Address(es): \\ ${ }^{1}$ Biology Department, Faculty of Science, Taibah University, Al-Sharm, Yanbu El-Bahr 46429, Saudi Arabia. \\ ${ }^{2}$ Botany and Microbiology Department, Faculty of Science, Zagazig University, 44519, Egypt. \\ ${ }^{3}$ Bioprocess development Department, Genetic Engineering and Biotechnology Research Institute (GEBRI), City for Scientific Research and Technology Applications, \\ New Borg EL-Arab, 21934, Alexandria, Egypt. \\ ${ }^{4}$ Botany and Microbiology Department, Faculty of Science, Cairo University, 12613 Giza, Egypt. \\ ${ }^{5}$ Plant Protection and Biomolecular Diagnosis Department, Arid Lands Cultivation Research Institute, City for Scientific Research and Technology Applications New \\ Borg EL-Arab, 21934, Alexandria, Egypt.
}

*Corresponding author: sabdellatif@srtacity.sci.eg

doi: 10.15414/jmbfs.2020.9.6.1204-1210

\section{ARTICLE INFO}

Received 22. 10. 2019

Revised 22. 1. 2020

Accepted 4. 2. 2020

Published 1. 6. 2020

Regular article

open $\partial_{\text {AcCESS }}$

\section{ABSTRACT}

Kombucha has become a flavored tea drink fermented with a symbiotic community of fungi, yeast, and bacteria. Kombucha has been reported to show functional medicinal importance attributed to the presence of some critical metabolites and bioactive compounds. We developed kombucha on three different substrates like black tea, green tea, and Psidium guajava (guava) juice extract. Kombucha enriched with guava extract showed maximal growth in terms of weight (fresh and dry) and moisture percentage. Further, the total phenol, total flavonoid, and characterization of different phenolic compounds like gallic acid, catechin, guaiacol and coumaric acid with guava juice extract fermented kombucha exhibiting maximal production. Also, the high DPPH (2,2-diphenyl-1-picryl-hydrazyl-hydrate) radical scavenging activity over the control. The kombucha tea fermented on guava extract showed significant antimicrobial activity against eleven human pathogenic bacterial strains and four pathogenic fungi. From the current study, we conclude that the preparation of kombucha tea using guava juice extract might be used as a supplementary food product due to its high nutritional value.

Keywords: Total phenols, Total flavonoids, DPPH, HPLC, kombucha tea, antibacterial and antifungal activity

\section{INTRODUCTION}

Kombucha is a traditional, non-alcoholic tea beverage fermented by a symbiotic community of osmophilic yeast and acetic acid bacteria (Acetobacteraceae) as symbiotic microbial consortium that is involved in the fermentation of green and black teas (De Filippis et al., 2018). Kombucha tea beverage is prevalent in various regions and is still not completely known in light of its progress (Felice $\boldsymbol{e t}$ al., 2013). Kombucha tea has a pleasant and a positive human health benefit all around the world (Kapp and Sumner, 2019).

The name of Kombucha is said to have come from Dr. Kombu, the Korean physician who took fermented tea to Japan for healing the Inkyu emperor. Kombucha has come from the north eastern China (Historical Manchuria). Tea was finally brought to Europe in the early 20th century as a result of commercial expansion, especially in Russia (as Kambucha) and Germany (as Kombuchashwamm) (Alexandru et al., 2019).

This traditional fermented beverage is known for its nutraceutical properties and health benefits (Dufresne and Farnworth, 2000; Jayabalan et al., 2014). The beverage has obtained considerable reputation mainly on the Western side due to numerous remarks concerning its therapeutic prospective towards several diseases. Several of its beneficial effects are established for instance; antimicrobial, antidiabetic, anticancer and antilipidemic effects (Gaggia $\boldsymbol{e t}$ al., 2018a). Drinking kombucha was recorded to improve the mood of the immune system; protect from cancer and cardiovascular disease (Watawana et al., 2015). To date, significant advancement in kombucha tea studies and its positive impacts has been achieved in the last century (Martínez et al., 2018). Achieved a self-prescribed remedy for numerous ailments like digestion problems, arthritis, prevention of microbial infection, combating stress, AIDS and immunity enhancement (Sai Ram et al., 2000). It has been established that antimicrobial behavior against a variety of infections, Kombucha antioxidant and antibacterial activity against E. coli, Salmonella sp and Staphylococcus aureus has recently been confirmed (Battikh et al., 2013a, Jayabalan et al., 2014). Kombucha tea fermentation is considered by a range of bacteria and yeast as a product of microbial action. Kombucha tea is a symbiotic culture of acetic acid bacteria like
Acetobacter aceti, Acetobacter pasteurianus, Gluconobacter oxydans, and yeasts mostly Saccharomyces sp., Zygosaccharomyces kombuchaensis, Torulopsis sp., Pichia membranaefaciens, Brettanomyces sp. (Borkani et al., 2016). The main component of Kombucha tea is the light cellulose pellicle layer and the sour liquid broth (Goh et al., 2012).

The microbes accumulate forming a firm cellulosic biofilm in the liquid-air interface during fermentation. which may act as a public good providing protection from invaders, storage for resources, and greater access to oxygen for microbes embedded within it (May et al., 2019). On the other hand, the majority of the biofilms examined so far are shaped either on a liquid-solid or air-solid interface (Chakravorty et al., 2016a).

Kombucha tea can be generated when the cultivation medium is supported by the high values of nitrogen sources in the form of purine derivatives like caffeine and theophylline for tea fungus culture (Malbasa, 2004). In general, the substratum of fermenting kombucha, i.e. green or black tea extract is sugared by addition of 5 to $8 \%$ sucrose and in addition to these traditionally substrates alternative substrates have been addressed such as Pepsi, grape juice, balsamic vinegar, vinegar, Jerusalem artichoke extract and milk (Essawet et al., 2015). Later, the several trails are being approved by the preparation of kombucha by substrates, other than black and green teas, such as Jerusalem artichoke tuber extracts, wine, milk, fruit juices and medicinal herbs like lemon balm, thyme, peppermint and sage (Jayabalan et al., 2014; Velićanski et al., 2013). At the end of the fermentation process, the chemical composition analysis in Kombucha foucsed on the active constiuents which confer to the fermented beverage its nutritional and antioxidant value, Kombucha is rich in organic acids (acetic, glucuronic, gluconic acids), vitamins and tea polyphenols (Jayabalan et al., 2014). Recently, (Jayabalan et al., 2007) characterized the fermentation process of guava leaves infusions by kombucha and studying possible chemical changes in their polyphenolic profile. The antimicrobial activity of Kombucha against pathogenic microorganisms is primarily attributed to antibiotics, acetic acid and other metabolites that generated in it (Sreeramulu et al., 2000a, 2001a). These metabolites are mainly polyphenols and tannins, which significantly inhibit a broad spectrum of gram-positive and negative bacteria. Later, the anti- 
bactericidal activity of tea was found to be due to polyphenols, particularly catechins (Gopal et al., 2016).Guava (Psidium guajava) is a tropical frui cultivated in tropical countries. Guava fruits and leaves have been used as traditional medicine for a long time (Díaz-de-Cerio et al., 2017). Several studies showed that guava leaves could be used as anti-inflammatory, hypoglycemic, antibacterial, antidiarrheal and antioxidant properties (Naseer et al., 2018).

the free radicals generated in our body by providing an electron can be overcome by antioxidants, where the body is confused with free radicals and the antioxidant defense is low so making disorder. Comparable to non-fermented tea, kombucha fermented tea has phenolic content effective for the antioxidant potency (Yang $\boldsymbol{e t}$ al., 2008; Vīna et al., 2014). Antioxidants can assist to prevent of autoimmune disorders, Alzheimer's, rheumatism, metabolic diseases, asthma and kidney dysfunction (Dufrense and Fanworth, 2000). We conduct DPPH assay to verify the antioxidant effect. The DPPH scavenging capacity of the sample is the principle of this assay. The electron providing capability of the samples is confirmed by lightening the purple reagent of DPPH into a yellow color (Sharma and Bhatt, 2009). Moreover, Kombucha has demonstrated antimicrobial properties. Greenwalt $\boldsymbol{e t} \boldsymbol{a l . ,}$ (1998) referred the antimicrobial action of kombucha to its acetic acid content and the existence of particular particles in kombucha post fermentation as catechins (Bhattacharya et al., 2017).

It can be hypothesized that the therapeutic efficacies can differ with the adjustment in media and fermentation time. However, to what extent they may vary is not known (Gaggìa et al., 2019).. To the best of our knowledge, no study has dealt with the investigation on variation in medium culture with kombucha guava juice fermentation. And its effects on kombucha's antioxidant, polyphenols, flavenoids antimicrobial and antifungal activities. So our study will focus to cover these gabes.

\section{MATERIALS AND METHODS}

\section{Preparation and fermentation of Kombucha}

\section{Tea fungus}

The process of fermentation was carried out using the local Kombucha (starter of tea fungus), as a symbiotic growing fungus in the sugar-cropped acetic acid bacteria and yeasts. This mixture of microorganisms was cultured in a pancakelike zoogloeal mat According to Jarrell et al., (2000). 10\% (v/v) kombucha (tea fungus) suspension was prepared by adding $100 \mathrm{~g}$ sugar (El aksaa factory, Egypt) and $4 \mathrm{~g}$ black and green tea leaves (supplied from the local tea store) to $1 \mathrm{~L}$ distilled $\mathrm{H}_{2} \mathrm{O}$. The mixture was boiled and allowed to cool down at room temperature. After cooling the mixture, it was filtered through sterile nylon mesh in order to remove the tea leaves and the filtrate was sterilized at $121^{\circ} \mathrm{C}$ for 15 min. After cooling, it was inoculated with $10 \%$ Kombucha starter mats that had grown and maintained in the same medium. , In order to keep the mixture in the best possible aseptic condition, the fermentation process was done in a sterile ja covered with clean sterile cheesecloth. In addition, the jar was tightly locked by rubber bands and then incubated at room temperature $\left(25-30^{\circ} \mathrm{C}\right)$ for seven days in a dark place and in a static state.

\section{Preparation of Guava Kombucha tea}

Fresh P. guajava L. fruits were collected from a farm in Borg El-Arab, Alexandria (Egypt), on June 2016. Fresh guava juice prepared as described earlier (Chiari et al., 2012) by soaking $10 \mathrm{~g}$ of fresh guavas in $0.2 \%$ sodium hypochlorite solution for 20 minutes. After that guava fruits were rinsed in distilled water, cut into small pieces in $100 \mathrm{ml}$ distilled $\mathrm{H}_{2} \mathrm{O}$, milled and filtered through filter paper. For the kombucha preparation, the substrate of traditional fermentation was substituted by $10 \%$ Guava fruit extract instead of the green or black tea. $10 \%$ of Kombucha starter was inoculated and incubated for a week at room temperature $\left(25-30^{\circ} \mathrm{C}\right)$ for the formation of Kombucha fungus form. After the preparation of traditional kombucha tea and Guava Kombucha tea, all cultures were centrifuged at $10,000 \mathrm{rpm}$ for 5 minutes. The supernatant was filtered and used for further investigations. The entire fermentation procedures were carried out inside a sterile laminar flow using sterilized glass wears which were heated up to $160^{\circ} \mathrm{C}$ for three hours at a hot air oven.

\section{Investigation of some conditional parameters}

Some conditional parameters had been investigated to optimize the culture for the production of Kambucha on guava juice extract at a shake-flask level. These tested conditions were: shaking speed, temp., $\mathrm{pH}$, inoculum concentration and sugar concentration. zero, 100 and $150 \mathrm{rpm}$ shaking speed were checked using $100 \mathrm{~mL}$ culture in 250 Erlenmeyer flasks. Temperature is a crucial parameter to be tested as it has a direct impact on kombucha productivity. The quantification of development of kombucha by assessing its dry weight at four degrees, we incubate kombucha extract at different temperature values at 25, 30, 37 and 45 . Three $\mathrm{pH} ; 7,8$ and 9 were also tested. The $\mathrm{pH}$ value was evaluated using an electronic $\mathrm{pH}$ meter calibrated at $\mathrm{pH} 4.0$ and 7.0 (HI 9321, Hanna Instruments,
USA). The other factor studied was the effect of kombucha inoculum concentration as $1.0 \%, 10 \%$ and $20.0 \%$ incubating in the static state, measuring dry weight for kombucha inoculum growth at the end of the experiment. Finally, the effect of different sugar concentrations supplemented to Komboucha culture was tested at $1 \%, 2.5 \%, 5 \%$, and $10 \%$. At the end of each experiment, Kombucha formation was examined and its dry weight determined after 15 days of incubation period at $30{ }^{\circ} \mathrm{C}$.

\section{Kombucha biomass and moisture content}

Kombucha fresh weight was determined by removing the cellulose floating net from the surface of the fermentative broth, rinsed twice with distilled water and weighed. This fresh biomass of Kombucha was dried in a warm air oven at $60^{\circ} \mathrm{C}$ to determine the dry weight. After that the moisture content of each sample was calculated as follows:

Moisture $(\%)=$ fresh wt. - dry wt. $/$ fresh wt. $\times 100$

\section{HPLC profiling for polyphenols}

All the standards compounds used for HPLC analysis were analytical grade and purchased from Sigma-Aldrich Chemical Company (Sigma, USA). The black, green and guava kombucha tea was chemically characterized using HPLC to determine the polyphenols content according to the method described by (Ochanda et al., 2015). Five $\mathrm{mL}$ of kombucha tea sample was eluted in $25 \mathrm{~mL}$ methanol and filtered into HPLC vials. The filtrate obtained was subjected to analysis by Agilent 1100 , American. Ten $\mu \mathrm{L}$ sample of the filtrate was injected to the HPLC system equipped with a diode array detector (SPD-M10Avp). Phenomenex Luna C- 18(2) column (4.6 mm ID $25 \mathrm{~cm}, 5 \mathrm{ml})$ was used for testing purposes. The mobile phase consisted of a mixture of $0.1 \%$ orthophosphoric acid and acetonitrile. Samples for the determination of HPLC analyses were filtered through a sterile microfilter $(0.22 \mu \mathrm{m})$ to remove any immpuriries. Polyphenols were recorded at $280 \mathrm{~nm}$ and HPLC resolution peaks recorded according to each compound's retention time. The concentrations of tea polyphenols were quantified from standard curves.

\section{Standard and sample preparation}

A stock standard solution $(100 \mu \mathrm{g} / \mathrm{mL})$ of each phenolic compound was prepared in methanol by weighing out approximately $0.0050 \mathrm{~g}$ of the analyte into $50 \mathrm{ml}$ volumetric flask. All standard solutions were stored in the dark at $5^{\circ} \mathrm{C}$ and were stable for at least three months.

The calibration curves of the standards were made by serial dilution of the stock standards (five set of standard dilutions) with methanol to yield 5, 10, 20, 40 and $80 \mu \mathrm{g} / \mathrm{mL}$ for each standard, and constructed the calibration curves were chromatograms as peak area vs. concentration of standard.

The mixed standard solution was prepared by dilution the mixed stock standard solutions in methanol to give a concentration of optimum peak $(5 \mu \mathrm{g} / \mathrm{mL})$ for each polyphenols.

Prepare the sample by dissolving it in methanol at the selected concentration of $5 \mathrm{mg} / \mathrm{mL}$. The samples were stored in the dark at low temperature $\left(5^{\circ} \mathrm{C}\right)$.

\section{Determination of total phenol content (TPC)}

Total phenol content in the kombucha tea fermented on guava extract was measured spectrophotometriclly (Jenway, Chelmsford, UK) by Folin-Ciocalteu (F.C.) colorimetric method using gallic acid as the standard with differen concentrations $(0.01-0.1 \mathrm{mg} / \mathrm{ml}), 10 \mathrm{ml}$ tea is mixed with $80 \%$ methanol and left for $24 \mathrm{~h}$ at room temperature before centrifuging it at $15,000 \mathrm{~g}$ for $10 \mathrm{~min} .1 .0 \mathrm{ml}$ of methanol extract was mixed and left out at $25^{\circ} \mathrm{C}$ for 30 minutes in $5 \mathrm{ml}$ of distilled water and $250 \mu \mathrm{L}$ of Folin-ciocalteau reagent. Then $1 \mathrm{ml}$ of $\mathrm{Na}_{2} \mathrm{CO}_{3}$ and distilled water, were added. The mixture was incubated at $25^{\circ} \mathrm{C}$ for an hour. The absorption of the developed blue color was measured at the $725 \mathrm{~nm}$ using the spectrophotometer. A gallic acid standard curve for phenolic content was constructed (Stewart et al. 1981) and the concentration was expressed as $\mathrm{mg}$ of gallic acid equivalents (GAE) per $g$ of dry weight (DW).

Preparation of standard- $0.5 \mathrm{ml}$ of each standard dilution added to $5 \mathrm{ml} \mathrm{F.C}$ reagent and $4 \mathrm{ml} \mathrm{Na} \mathrm{CO}_{3}$ solution. Absorbance measured at $765 \mathrm{~nm}$ after 15 minutes.

Blank solution - Add $0.5 \mathrm{~mL}$ methanol and $5 \mathrm{~mL}$ F.C. reagent to $4 \mathrm{~mL} \mathrm{Na}_{2} \mathrm{CO}_{3}$ solution, calibration curve was plotted for further determination of

\section{Total flavonoid content (TFC)}

Total flavonoid content was determined according to Ahmad et al. (2014) with slight modification. $5 \mathrm{ml}$ of each tea are sonicated in $10 \mathrm{~mL}$ methanol for $10 \mathrm{~min}$. 
After that $300 \mu \mathrm{L}$ extract was mixed with $3.4 \mathrm{ml}$ aqueous methanol (30\%) followed by the addition of $150 \mu \mathrm{L}$ sodium nitrite $(0.5 \mathrm{M})$ and $0.3 \mathrm{M}$ aluminum chloride. After five minutes, $1 \mathrm{~mL}$ sodium hydroxide $(1 \mathrm{M})$ solution added and a UV-visible spectrophotometer absorbance of $506 \mathrm{~nm}$ were detected. For calculation, a standard catechin calibration curve was used; A calibration curve of catechin was obtained by preparation standard catechin solutions $(100,200,400$, $600,800,1000 \mu \mathrm{g} / \mathrm{ml}$ ) in distilled water and the total flavonoid content of each extract was expressed as $\mathrm{mg}$ of catechin equivalents per gm of dry weight of sample.

\section{Determination of antioxidant activity}

DPPH test was used to measure antioxidant activity. $10 \mathrm{mlL}$ of every tea type were mixed with $100 \mathrm{~mL}$ methanol for $1 \mathrm{~min}$, centrifuged for $15 \mathrm{~min}$ at $4{ }^{\circ}$ at $10,000 \mathrm{rpm}, 100 \mu \mathrm{L}$ of the sample and $100 \mu \mathrm{L}$ of DPPH were mixed in the assay mix (prepared in methanol). The resultant mixture was incubated in the dark for 30 min at $25^{\circ} \mathrm{C}$ and absorbance were measured at $517 \mathrm{~nm}$ specro(Constanza et al., 2012). DPPH antioxidant activity was expressed as percentage DPPH scavenging.

\section{Antimicrobial activity}

The antimicrobial activity of Kombucha (Black, Green, Guava) was investigated against eleven human pathogenic bacterial strains, namely: Pseudomonas sp I Pseudomonas sp II, Klebsiella pneumonia, Klebsiella sp I, Klebsiella sp II, Acinetobacter sp I, Acinetobacter sp II, Proteus sp, coagulase-negative Staphylococci, Methicillin-resistant Staphylococcus aureus (MRSA) and E. coli, were collected from El Sadder hospital (Alexandria city, Egypt). Beside four fungal species namely: Aspergillus flavus, Fusarium oxysporium, Alternaria sp, and Trichoderma sp which were collected from the Faculty of Science, University of Alexandria (Alexandria city, Egypt). The bacterial and fungal species were cultivated on the surface of nutrient agar and potato dextrose aga plates, respectively by the swab method using sterile cotton applicators swabs. The antimicrobial activity of Kombucha was examined by using absorbent disc (Bauer et al., 1959). Shortly, an individual colony of each bacterium was injected in $5 \mathrm{~mL}$ of nutrient broth media and incubated for 24 hours at $30^{\circ} \mathrm{C}$. These bacteria were preferred as they are familiar individual infections. A sum of $0.1 \mathrm{~mL}$ broth from each culture was spread uniformly on nutrient agar (Sigma Aldrich, Germany) applying a spread plating rod or swap. Whattmans filter paper was needed to supply $0.5 \mathrm{~mm}$ discs. The discs were saturated with the kombuch samples and injected on the plates with the lawn of the pathogen by sterile forceps. The plates were incubated for 24 hours at $30^{\circ} \mathrm{C}$. We calculated the sector of inhibition post incubation.

The positive control was set up using $500 \mathrm{~g}$ amoxicillin and clavulanic with $20 \%$ concentration and negative control with unfermented guava juice for antibacteria activity. The antimicrobial activity of the Kombucha extract was estimated. The diameter of the inhibition zone at the end of incubation periods had been measured. Each experiment was performed three times and the average diameter \pm standard deviation was recorded for the inhibition zone.

\section{Statistical analysis}

Data of kombucha with different growth substrates were collected, checked, revised, and presented in tables using SPSS V.16 and Microsoft Excel 2016 after being subjected to outlier detection and statistical normality test to detect whether the data are parametric or nonparametric. Then calculate statistically significant differences at the $P<0.05$ level are indicated.

\section{RESULTS}

Guava suspension produced a distinct creamy color Kombucha that may refer to the chemical composition and natural color of the medium. The fermentation results of kombucha suspension in terms of fresh and dry weight and moisture percentage are presented in Table1. Kombucha fermented on guava juice substrate showed a higher fresh and dry weight, then followed by black tea and finally the kombucha fermented on green tea substrate are the lowest in its fresh and dry weight. While the moister percentage was high in black tea followed by guava and finally lowest in green tea.

Table 1 Growth of Kombucha on different substrates measured in terms of fresh and dry weight and moisture percentage.

\begin{tabular}{llll}
\hline \multirow{2}{*}{ Substrate } & \multicolumn{2}{l}{ Kombucha mats } & \\
& Fresh wt. (gm) & Dry wt. $(\mathbf{g m})$ & Moisture (\%) \\
\hline Black tea & $2.25 \pm 0.07^{* *}$ & $1.83 \pm 0.07^{* *}$ & $18.94 \pm 0.67 * *$ \\
Green tea & $1.58 \pm 0.1^{* *}$ & $1.38 \pm 0.1^{* *}$ & $12.45 \pm 2.21^{* *}$ \\
Guava juice & $\mathbf{2 . 3 3} \pm \mathbf{0 . 2 9 * * *}$ & $\mathbf{1 . 9 6} \pm \mathbf{0 . 2} * *$ & $16.07 \pm 3.04 * * *$ \\
\hline
\end{tabular}

Each value represents the mean of three replicates. $* * p<0.05$. $* * * p<0.01$.

\section{Optimization parameters}

By studying some physical conditions, we obtain (Fig. 1) a unique configuration of kombucha pellets due to shaking velocity which utterly different from that obtained by the static condition.

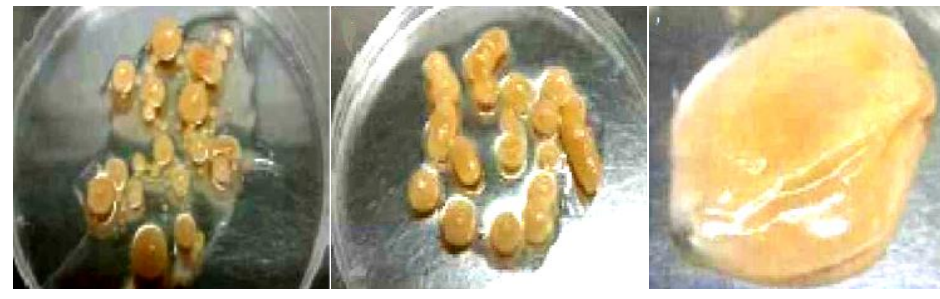

Shaking at $100 \mathrm{rpm} \quad$ Shaking at $150 \mathrm{rpm} \quad$ Static condition

Figure 1 Effect of shaking velocity on Kombucha profile

The best temperature for Kombucha growth was shown in (Fig. 2) at $30 \mathrm{C}^{\circ}$. The increases or decrease in temperature causes a distinct change in Kombucha development so that only the best degree for microorganisms of Kombucha scopy is $30 \mathrm{C}^{\circ}$ and decreased by elevating the temperature degree. By studying three $\mathrm{pH}$ values 7, 8 and 9 we showed (Fig.3) that the growth of kombucha was getting bigger and increasing by increasing $\mathrm{pHs}$ to a specific limit which indicates that $\mathrm{pH}$ has a crucial role to play in enhancing the community of kombucha. At $\mathrm{pH} 8$ giving the higheset dry weight.

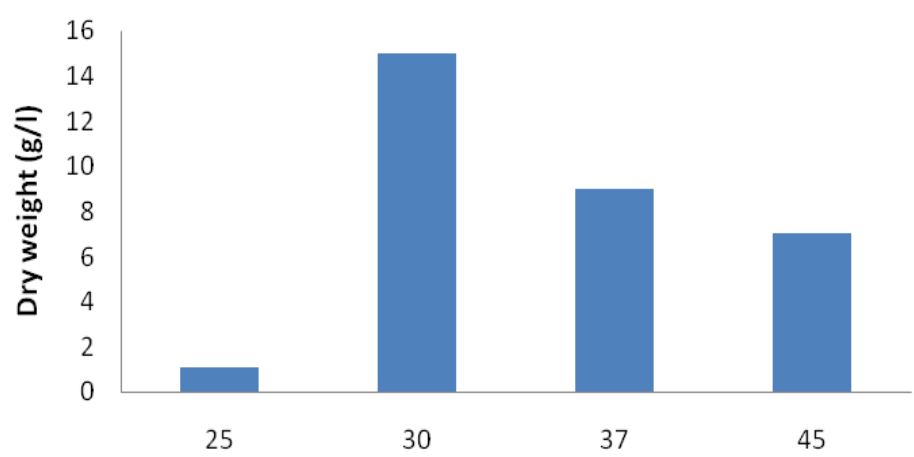

Temperature

Figure 1 Effect of temperature variation on dry weight $\%$ of kombucha

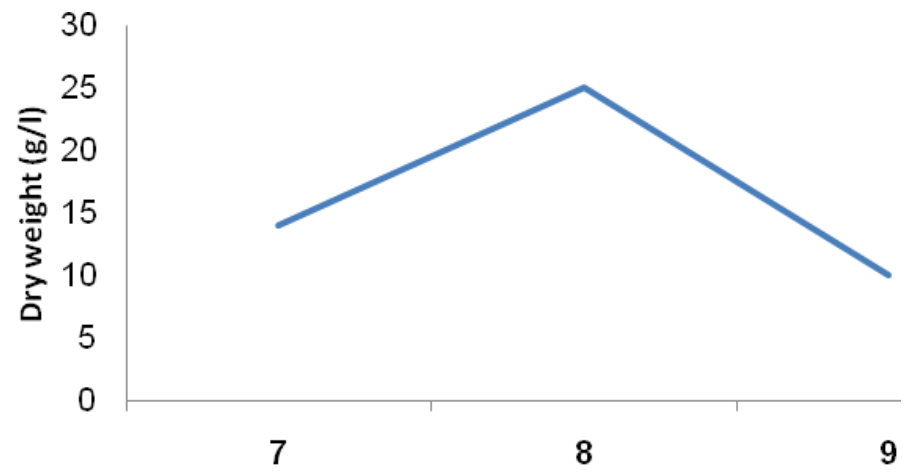

$\mathrm{pH}$

Figure 2 Effect of $\mathrm{pH}$ variation on dry weight of kombucha

As in (Fig 4), the largest proportion of Kombucha dry weight was produced by increasing inoculum proportion and vice versa. In this case, If organisms are concentrated in media which can promote the production of their metabolites, the thickness and dry weight of Kombucha raised as the tea extract surface produced a new layer. That is why: if the essential organisms are concentrated, it can predominate. Fig. 4 showed the highest dry weight (15 g/l) of Kombucha scopy reached at high inoculum \% (20\%) 
Kombucha supplementation by different sugar regime causing a different response in its flourishing. The lowest sugar level $(1 \%)$ resulted in Kombucha's lowest dry weight $(7 \mathrm{~g} / \mathrm{l})$ and reached to $1.5 \mathrm{~g} / \mathrm{l}$ at sugar concenteration $10 \%$. The positive and direct relationship between concentration of sugar and an increase of dry weight in Kombucha was shown in Fig. 5.

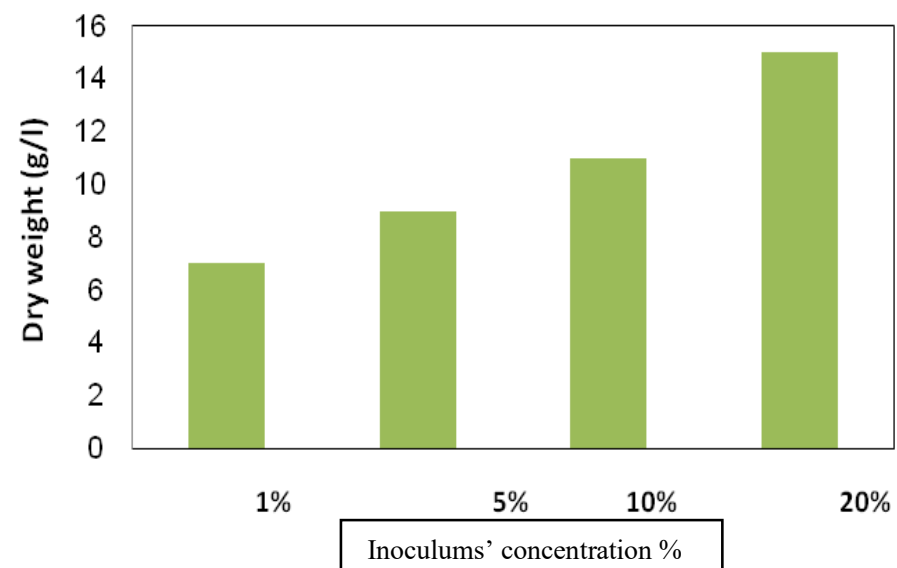

Figure 3 Effect of kombucha inoculum cocentratin on dry weight \% of kombucha
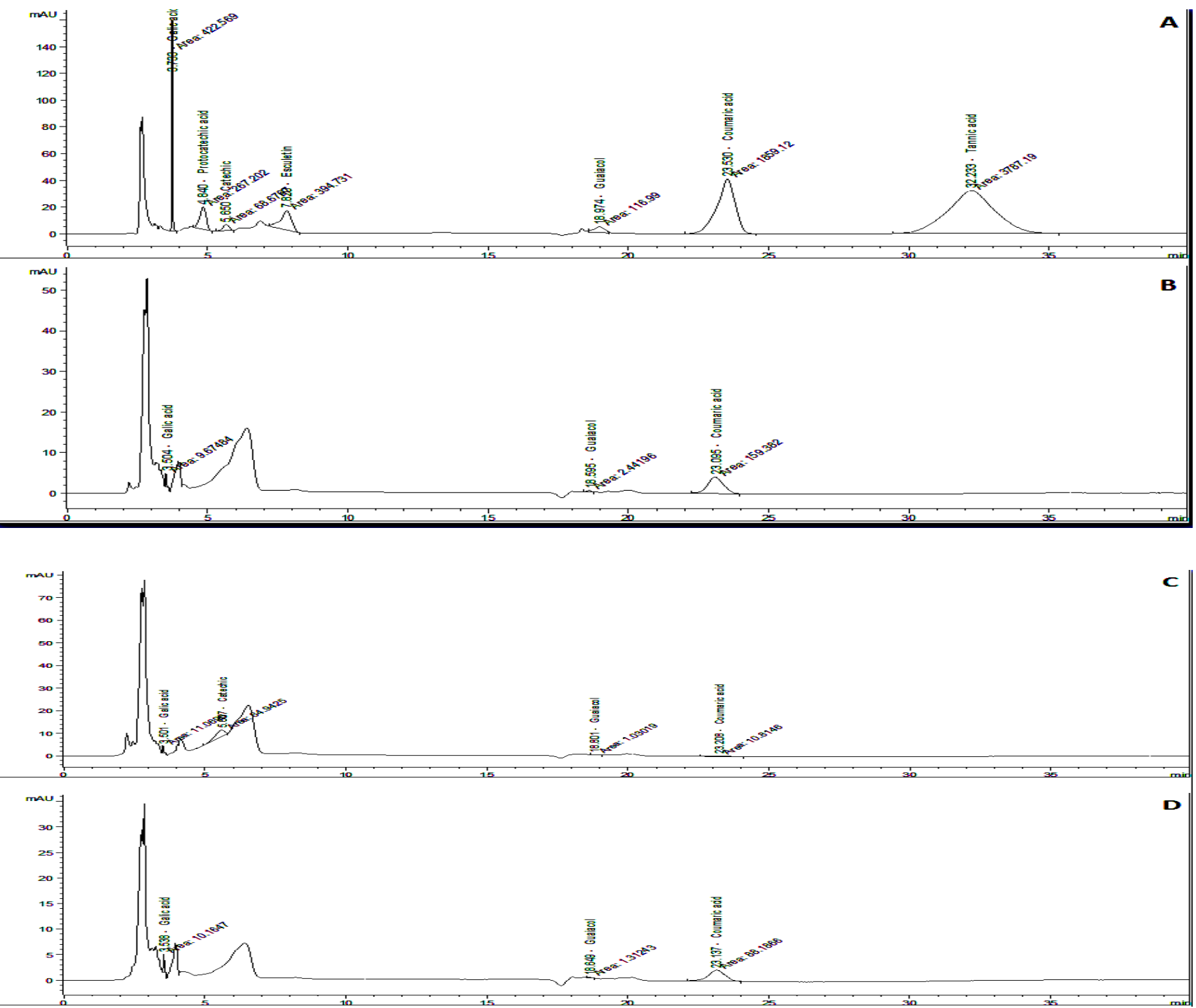

Figure 5 HPLC chromatograms of polyphenols compositions in different substrates used in kombucha fermentationprocess: standard mixture (A); green tea substrate (B); black tea substrate (C) and guava juice substrate (D)

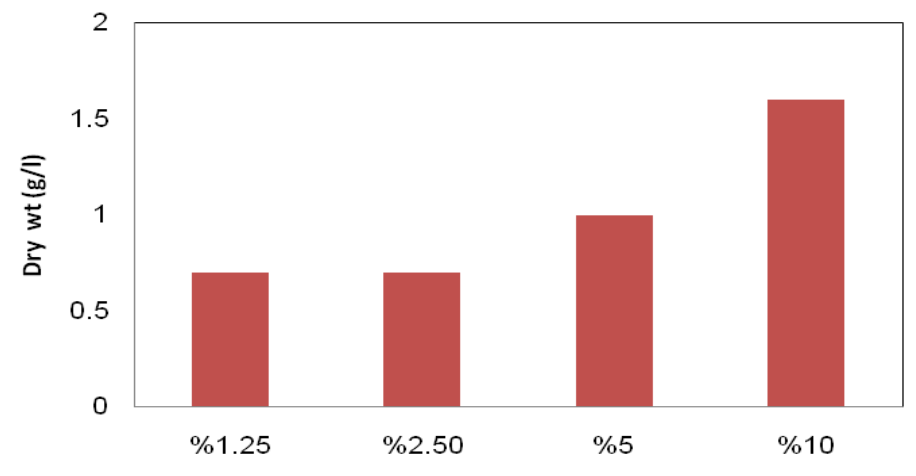

Figure 4 Effect of sugar concenteration on dry weight (g/l) of kombucha

\section{Biochemical and HPLC Profiling}

The HPLC chromatograms (Fig. 6A-D) depicting the results of polyphenols in the black, green and guava extract as a substrate for kombucha tea production in comparison with the standard mixture. It showed that the three types of kombucha tea are rich with polyphenols metabolites. The most prominent metabolites are gallic acid, catechin, guaiacol, and coumaric acid. The kombucha tea from the black tea has the lowest percentage of gallic acid, catechin, guaiacol and coumaric acid (Fig. 6B). On the other hand, the guava juice kombucha fermentation having the maximal presence of different metabolites like gallic acid, catechin, guaiacol, and coumaric acid compared to black and green tea (Fig. 6D).

$$
\text { || }
$$


In our study, we also observed that the presence of metabolites and polyphenols as revealed by the HPLC chromatogram lead to higher antioxidant activity in them furthermore, increase in total flavonoid and total phenol content (Table 2). Relative to control the fermented guava kombucha exhibited higher antioxidant activity which can be attributed to the presence of a higher quantity of flavonoids and phenols, could have also contributed to the greater antifungal and antibacterial activity.

Table 2 Total flavonoid (TFC, mg/g DW), total phenol content TPC, and total antioxidant activity of Kombucha fermented with guava juice

\begin{tabular}{llll}
\hline Treatment & $\begin{array}{l}\text { TFC } \\
\text { (mg catechin equivalent/g DW) }\end{array}$ & $\begin{array}{l}\text { TPC } \\
\text { (mg GAE equivalent/g DW) }\end{array}$ & $\begin{array}{l}\text { Total antioxidant activity } \\
\text { (\% DPPH scavenging) }\end{array}$ \\
\hline Control (Kombucha tea) & $18^{* *}$ & $180^{* *}$ & $155^{* *}$ \\
Kombucha treated guava & $57^{* *}$ & $360^{* *}$ & $410^{* *}$ \\
\hline
\end{tabular}

In the present study, the higher antioxidant activity in guava fermented kombucha guava extract which may be ascribed to the presence of a higher quantity of phenols and flavonoids revealed by HPLC chromatogram as well as quantification (Fig. 6A-1D, Table 2)

\section{Antimicrobial activity}

The obtained results for antimicrobial activity of the black, green and guava as a substrate for kombucha fermentationproduction was investigated against eleven human pathogenic bacterial strains (Pseudomonas sp I, Pseudomonas sp II, Klebsiella pneumonia, Klebsiella sp I, Klebsiella sp II, Acinetobacter sp I, Acinetobacter sp II, Proteus sp, coagulase-negative Staphylococci, Staphylococci (MRSA) and E. coli) and four fungal species (Alternaria sp. Aspergillus flavus, Fusarium oxysporium and Trichoderma sp) using absorbent disc method. The diameter of inhibition zones (mm) around each well with kombucha tea extract was represented in Table 3 and Table 4; The three kombuchas, i.e., kombucha on black tea, green tea, and guava juice showed a potent antibacterial activity and antifungal activity. It was observed that kombucha grew on the guava juice significantly $(\mathrm{P}<0.05)$ displayed maximal antifungal activity against Alternaria sp. Aspergillus flavus, Fusarium oxysporium (Table 3). While the Trichoderma sp. showed the highest antifungal activity within kombucha green tea.

Table 3 Antifungal activity of Kombucha fermented with black, green tea and guava juice against the Alternaria sp., Aspergillus flavus, Fusarium oxysporium and Trichoderma sp. fungal species

\begin{tabular}{|c|c|c|c|}
\hline \multirow{2}{*}{ Fungal species } & \multicolumn{3}{|c|}{ Inhibition zone diameter $(\mathrm{mm})$ from Kombucha extract } \\
\hline & Black tea & Green tea & Guava juice \\
\hline & $15.05 \pm 0.06 * *$ & $12.98 \pm 0.07 * *$ & $24.06 \pm 0.04 * * *$ \\
\hline Aspergillus flavus & $14.39 \pm 0.54 * *$ & $12.74 \pm 0.56 * *$ & $21.04 \pm 0.04 * * *$ \\
\hline Fusarium oxysporium & $13.77 \pm 0.59 * *$ & $17.17 \pm 0.96 * *$ & $21.73 \pm 0.56^{* * *}$ \\
\hline Trichoderma $\mathrm{sp}$. & $16.41 \pm 0.09 * *$ & $22.15 \pm 0.07 * *$ & $20.99 \pm 0.09 * *$ \\
\hline
\end{tabular}

* Each value represents the mean of three replicates. ${ }^{* *} p<0.05$. $* * * p<0.01$.

Concerning the antibacterial activity, the kombucha grown on the guava juice were effectively inhibited most of the bacterial growth, while it was prominent with a higher diameter of inhibition zones with Pseudomonas sp. I, Klebsiella sp. I and Staphylococcus (MRSA) (Table 4).

Table 4 Antibacterial activity of Kombucha fermented with guava juice against the selected bacterial isolates

\begin{tabular}{ll}
\hline Bacterial isolates & Inhibition zone diameter $\mathbf{~ m m})$ \\
\hline Acinetobacter sp. I & $24.02 \pm 0.08^{* *}$ \\
Acinetobacter sp. II & $0.0 \pm 0.0^{* *}$ \\
E. coli & $0.0 \pm 0.0^{* *}$ \\
Klebsiella pneumonia & $26 \pm 0.08^{* *}$ \\
Klebsiella sp. I & $26.98 \pm 0.09^{* *}$ \\
Klebsiella sp. II & $0.0 \pm 0.0^{* *}$ \\
Pseudomonas sp. I & $29.01 \pm 0.1^{* * *}$ \\
Pseudomonas sp. II & $24.03 \pm 0.14^{* *}$ \\
Proteus sp. & $24.03 \pm 0.06^{* *}$ \\
Staphylococcii (coagulase $-\mathrm{ve})$ & $15.99 \pm 0.1^{* *}$ \\
Staphylococci (MRSA) & $25.01 \pm 0.07^{* *}$ \\
\hline * Each value represents the mean of three replicates. ${ }^{* *} p<0.05 . * * * p<0.01$.
\end{tabular}

\section{DISCUSSION}

The obtained results for the fresh and the dry weight of the kombucha tea and the higher observed values from the guava juice as a substrate are following the observed previously by (Nuria Elizabeth et al., 2018); they observed the oscillating behavior of guava as a substrate for kombucha tea production. SB and L (2011) stated that the differences within several substrates could be related in the function of the strain used for fermentation. In the present work, the main microorganism present in the consortium is acetic acid bacteria and yeast species which are reported to flourish and increase when the substrate is guava rather than green or black tea (Gaggìa et al., 2018b).

In contrast to unfermented specimens, results showed a significant lowering in dry mass for kombucha tea brews in samples of black and green tea kombucha and the most significant decrease in dry mass was evaluated during the storage process. Kombucha fermentation product contents were found to depend mainly on the composition of the layer of kombucha microbiota and produced enzymes liberated by bacteria and yeast during kombucha fermentation (Jayalaban $\boldsymbol{e t}$ al., 2008). Other authors suggested that the system's nitrogen containing compounds should be directly related to the improvements in the biomass yield (Malbaša $\boldsymbol{e t}$ al., 2011). It was noted that in systems with molasses the level of the biomass was higher than with sucrose; This is because kombucha microflora uses up sugar actively during the growth of the kombucha strain as a carbon source. That is what is shown with our results; by elevating the sugar concentration up to $10 \%$ giving parralel increase in dry weight of Kombucha scopy reaching 1,5 g/l. Moreover, increasing in inoculum percentage up to $20 \%$ giving rise to increase in community number of scopy. From these studies, it is clear that the environment has an impact on the composition of community members of Kombucha; there is no apparent "canonical" species composition across all substrates and all culture conditions (May et al., 2019).

Kombucha has appeared in recent years as a fortified, enriched and enhanced efficient food item that can have a potential health impact (Sinir et al., 2019). The most prominent phytochemicals and antioxidants present in any diet are polyphenols (Amarasinghe et al., 2018). Polyphenols provided by fruits, vegetables in any foodstuffs; cereals, vegetables, natural fruit juices, tea, coffee and red wine (Scalbert et al. 2005; Pandey and Rizvi, 2009). Due to its presence as a functional food, kombucha is mainly intensified by polyphenols and other secondary metabolites produced during fermentation, therefore imparting therapeutic effects (Watawana et al., 2015)

In the present study, we observed that the guava juice kombucha fermentation showed the presence of higher number and the greater content of polyphenols and secondary metabolites as revealed by the HPLC profiles (Figure 6A-D) and therefore may directly contribute to its increased medicinal importance. It has been reported that during the Kombucha fermentation many compounds exhibiting radical scavenging properties were released from the tea leaves themselves (Malbaša et al., 2011) and among them are included the polyphenols and catechins that belonging to flavanol group (Battikh et al., 2013b). Polyphenols have broad antioxidant properties due to their ability to scavenge free radicals and reactive oxygen species (ROS) (Sánchez, 2017). Polyphenols make up almost $30 \%$ of the total dry weight of fresh tea leaves which includes the prominent compounds found as epigallocatechin, epigallocatechin-3-gallate, epicatechin-3-gallate, and epicatechin (Lee et al., 2017). A DPPH radical scavenging measure is utilized to describe the substance cancer prevention agent limit within sight of free radicals (Garcia et al., 2012). Published studies demonstrate that tea polyphenols are mainly antioxidants, characterized by a elevated DPPH radical scavenging potential that their antioxidants activity up to 100 folds higher than vitamin c (Gramza-Michalowska et al., 2016). Tea polyphenols are effectively playing a preventive effect in oxidative changes of the substrate (Sajilata et al., 2008; Papuc et al., 2017). Previously, the radical activity property of kombucha tea made from green tea, black tea and tea waste material was reported by Jayabalan et al., 2008 but kombucha fermented guava juice's antioxidant property is much less worked out. During the kombucha fermentation, the acidic environment establishes complex phenolic compounds and the presence of bacterial and yeast-liberated enzymes in tea fungus leads to the degradation of complex molecules into small ones resulting in a massive increase in Kombucha tea broth polyphenolic compounds (Jayabalan et al., 2007, 2017). Therefore, the duration period of fermentation and the starter origin are essential for increasing the phenolic content accumulation leading to higher radical scavenging activity (Chu and Chen, 2006; Jayabalan et al., 2007, 2017; Malbaša et al., 2011). kombucha grew on guava juice substrate was screened for its antibacterial activity against certain prime disease-causing bacteria. As shown from resultsthe kombucha that grown on the guava juice efficiently suppress the former bacterial growth more efficiently i.e Acinetobacter Sp. I, Klebsiella pneumonia, Pseudomonas sp. II, Proteus sp., Staphylococci (coagulase -ve). On the other hand, the kombucha grown on the guava juice cannot stop the growth of Acinetobacter sp., II, Klebsiella sp. II and E. coli (Table 3). This is can be attributed to the previous results that demonstrated the insufficient antibiotic 
quality and mistreatment can give rise to resistance and complexity in trying to treat infectious diseases caused by bacteria (Kolár et al., 2001). The emergence of resistance to many of the antimicrobial agents has increasingly and complicated the E. coli infection treatments (Penchovsky and Traykovska, 2015). In recent times, the emergence of resistant strains of human diseases associated pathogens have been widely seen and antimicrobial use and antifungal product of Kombucha tea can be used to overcome this problem (Battikh $\boldsymbol{e t}$ al. 2013a). Antifungal behavior of Kombucha was induced by higher production of acetic acid in this beverage. That can be explained as the undissociated particles of the acid produced during fermentation could get into the bacterial or fungal unit and the dissociation would get place in the cytoplasm and suppress the organism production (Cetojevic-Simin et al., 2008). So kombucha and its components are excellent candidates for the emergence of new pathogen fighting drugs and microorganisms (May et al., 2019). Study by Bhattacharya et al., (2017) proved that the growth of microorganisms can be destroyed by isorhamnetin and catechins of kombucha in a quantified condition. Agree with our results Kombucha tea has demonstrated to inhibit the growth of pathogens such as Helicobacter pylori (the causative organism of peptic ulcers), Entamoeba cloacae, Pseudomonas aeruginosa, Staphylococcus aureus, Staphylococcus epidermis, Agrobacterium tumefaciens, Bacillus cereus, Aeromonas hydrophila, Salmonella typhimurium, Salmonella enteritidis, Shigella sonnei, Leuconostoc monocytogenes, Yersinia enterocolitica, Campylobacter jejuni and Candida albicans (Steinkraus et al., 1996; Dufresne and Farnworth, 2000; Sreeramulu et al., 2000b). Another observed points that antimicrobial broth activity is attributed to the low $\mathrm{pH}$ value of the drink given by the presence of acetic acid and a range of other compounds such as catechins and many proteins produced during fermentation (Sreeramulu et al., 2001b). pH is among the most significant environmental variables for Kombucha fermentation, as the biological operations of the resulting fizzy drinks might be induced by some acids formed as acetic acid and gluconic acid (De Filippis $\boldsymbol{e t}$ al., 2018; Gaggìa $\boldsymbol{e}$ al., 2019). The $\mathrm{pH}$ records achieved during this operation were in line with earlier investigation which suggested that weaker $\mathrm{pH}$ alterations could be linked with the impact of buffering from reactions between common enzymes and minerals from the substratum after three days of fermentation (Loncar et al., 2000, Malbaša $\boldsymbol{e}$ al., 2011). The carbon gas released during the fermentation process dissociates and generates amphiprotic ( $\mathrm{HCO}_{-}-$) hydrocarbonate anion. This anion responds with hydrogen ions of the current organic acids readily, stopping further $\mathrm{pH}$ modifications, thus adding to the system's buffer feature (Cetojevic-Simin, et al. 2008). It is interesting to note, that the extended fermentation period will encourage the phenolic material and the antioxidant operate but will not raise the acidic flavour. Owing to greater antioxidant action and elevated prospective safety advantages, 12 days of fermentation are proposed not more as the reduction of both the phenolic content and that of the antioxidant action and the microbial population for kombucha tea used with the substrate have been noted (Muhialdin et al., 2019). acetic acid and catechins have been well informed about the potential to inhibit a range of gram-positive and gram-negative microorganisms (Jayabalan et al., 2014). Also of the presence of acetic acid and other acids, the contribution of other biologically active components like phenolic compounds arising as bacteriocins, proteins, enzymes, leads to improved antimicrobial activity (Battikh et al., 2012; Hobbs, 1995). Further investigators suggest that the presence of antibiotic substances in broth strengthens the antimicrobial property of kombucha (Sreeramulu et al., 2000a, 2001b). The composition differences and biological activities of the scopy microorganisms may be affected by different parameters like type of species, sugar densities, fermentation times, temperatue and proportions of scopy (Wolfe and Dutton, 2015). With the optimal temperature throughout the brewing process at $30 \mathrm{C}^{\circ}$ the additional benefits of fermentation were improved, leading to better microbial growth and enzyme activity. It also has a strong connection to the productivity of microbes as well as structural changes that could also affect antioxidant behavior in a compound found (Nguyen et al., 2015). Also, (Chakravorty et al., 2016b) assessed a high tendency of kombucha to produce polyphenol substance and antioxidant activities by increasing the time of brewing. The antimicrobial and antifungal properties of kombucha are mostly attributed to the presence of powerful symbiosis between bacteria and fung leading to the production of critical metabolites responsible for the inhibition of contaminating bacteria (Shahbazi et al., 2018). Mo et al., (2008) proposed the possibility of creative and exciting applications of fermented kombucha teas as direct antimicrobial inhibitors, as medicinal and biological preservatives in meat products.

\section{CONCLUSION}

From the present study, it can be concluded that kombucha tea prepared using the guava juice extract showed maximum content of polyphenols and the growth of kombucha scopy. Enhancement of DPPH scavenging activity of kombucha fermented guava extract was perhaps due to the increased synthesis of phenols and flavonoids. This could further be guidance for further inquiries concerning the interpretation of biochemical shifts in fermentation of kombucha. More research needs to be done concerning large scale production of fermented tea with different fruits flavor that could attract amazing applications. Moreover, the enhancement of a growing process from one level of the laboratory (pilot scale) into a market product (industrial scale) is also a future interest.

Acknowledgement: We would like to thank the Bioprocess dept. staff. of Genetic Engineering and Biotechnology application Institute, SRTA-City and botany department staff. of the faculty of science Cairo University, Egypt for all their facilities in our study performance.

\section{REFERENCES}

Ahmed, D., Fatima, K. \& Saeed, R. (2014). Analysis of phenolic and flavonoid contents, and the anti-oxidative potential and lipid peroxidation inhibitory activity of methanolic extract of Carissa opaca roots and its fractions in different solvents. Antioxidants, 3, 671-683. https://doi.org/10.3390/antiox3040671

Alexandru, G., \& Alina-Maria, H. (2019). Nutrients in Beverages In: (Volume 12) The Science of Beverages $1^{\text {st }}$ edition. Pp 592, Academic Press.

Amarasinghe, H., Weerakkody, N. S., \& Waisundara V. Y. (2018). Evaluation of physicochemical properties and antioxidant activities of kombucha "Tea Fungus" during extended periods of fermentation. Food Sci Nutr, 6, 659-665 https://doi.org/10.1002/fsn3.605

Battikh, H., Bakhrouf A., \& Ammar E.( 2012). Antimicrobial effect of Kombucha analogues. LWT - Food Sci and Technol, 47, 71-77. https://doi:10.1016/j.1wt.2011.12.033.

Battikh, H., Chaieb K., Bakhrouf A., \& Ammar E. (2013a). Antibacterial And Antifungal Activities Of Black And Green Kombucha Teas. JFood Biochem, 37, 231-236. https://doi.org/10.1016/j.lwt.2011.12.033

Bauer, A. W., Perry D. M., \& Kirby W. M. (1959). Single-disk antibioticsensitivity testing of staphylococci; an analysis of technique and results. A.M.A Arch Intern Med, 104, 208-16. https://doi:10.1001/archinte.1959.00270080034004

Bhattacharya, D., Ghosh, D., Bhattacharya, S., Srakar, S., Karmakar, P., Koley, H., \& Gachhui, R. (2017). Antibacterial activity of polyphenolic fraction of Kombucha against Vibrio cholerae: targeting cell membrane. Letters in Applied Microbiology, 66, 145-152. https://doi.org/10.1111/lam.12829

Borkani, R. A., Doudi M., \& Rezayatmand Z. (2016). Study of the Anti-Bacterial Effects of Green and Black Kombucha Teas and Their Synergetic Effect against Some Important Gram Positive Pathogens Transmitted by Foodstuff. Int J Adv Biotechnol Res, 1741-1747. http://www.bipublication.com

Cetojevic-Simin, D. D., Bogdanovic, G. M., Cvetkovic, D. D., \& Velicanski, A S. (2008). Antiproliferative and antimicrobial activity of traditional Kombucha and Satureja montana L. Kombucha. Journal of BUON, 13, 395- 401.

Chakravorty, S., Bhattacharya S., Chatzinotas A., Chakraborty W., Bhattacharya D., \& Gachhui R. (2016). Kombucha tea fermentation: Microbial and biochemical dynamics. Int. J. Food Microbiol, 220, 63-72. https:// doi:10.1016/i.ijfoodmicro.2015.12.015.

Chiari, B. G., Severi J. A., De Pauli-Credendio P. A., De Sylos C. M., Vilegas W., \& Corrêa M. A., ISAAC V. L. B. (2012). Assessment of the chemical profile, polyphenol content and antioxidant activity in extracts of Psidium Guajava L. fruits. Int J Pharm Pharm Sci, 4, 331-336. https://www.researchgate. net/publication/286492653

Choi, S.Y., Hwang J.-H., Park S.-Y., Jin Y.-J., Ko H.-C., Moon S.-W., \& Kim S.J. (2008). Fermented guava leaf extract inhibits LPS-induced COX-2 and iNOS expression in Mouse macrophage cells by inhibition of transcription factor NFкB. Phytother Res.,22, 1030-1034. https://doi:10.1002/ptr.2419.

Chu, S.-C., \& Chen C. (2006). Effects of origins and fermentation time on the antioxidant activities of kombucha. Food Chem, 98, 502-507. https://doi:10.1016/j.foodchem.2005.05.080.

Constanza, K. E., White B. L., Davis J. P., Sanders T. H., \& Dean L. L. (2012) Value-Added Processing of Peanut Skins: Antioxidant Capacity, Total Phenolics, and Procyanidin Content of Spray-Dried Extracts. J Agric Food Chem, 60, 10776-10783. https://doi:10.1021/jf3035258

De Filippis, F., Troise, A. D., Vitaglione, P., \& Ercolini D. (2018). Differen temperatures select distinctive acetic acid bacteria species and promotes organic acids production during Kombucha tea fermentation. Food Microbiology, 73,1116 https://doi.org/10.1016/j.fm.2018.01.008.

Díaz-De-Cerio, E., Verardo, V., Gómez-Caravaca, A., Fernández-Gutiérrez, A. \& Segura-Carretero, A. (2017). Health Effects of Psidium guajava L. Leaves: An Overview of the Last Decade. Inter J Mol Sci, 18, 897 https://doi.org/10.3390/ijms18040897.

Dufresne, C., \& Farnworth. E. (2000). Tea, Kombucha, and health: a review. Food Res Int, 33, 409-421. https://doi:10.1016/S0963-9969(00)00067-3.

Essawet, N., Cvetkovic, D., Velicanski, A., Canadanovic-Brunet, J., Vulic, J., Maksimovic, V., \& Markov, S. (2015). Polyphenols and antioxidant activities of Kombucha beverage enriched with Coffeeberry ${ }^{\circledR}$ extract. Chem Ind Chem Eng Q, 21, 399-409. https:// doi:10.2298/CICEQ140528042E.

Felice, F., Rossella, F., Maria, F. V., Letizia, P., \& Rosario, R. (2013). A compendium of the most common root canal irrigants.International $\mathrm{j}$ dent clin, 5,17-25. https://www.researchgate.net/publication/262809498

Gaggìa, F., Baffoni, L., Galiano, M., Nielsen, D., Jakobsen, R., Castro-Mejía, J., Bosi, S., Truzzi, F. Musumeci, Dinelli, F., \& Di Gioia, G. D. (2018). Kombucha 
Beverage from Green, Black and Rooibos Teas: A Comparative Study Looking at Microbiology, Chemistry and Antioxidant Activity. Nutrients, 11,1 . https://doi:10.3390/nu11010001.

Garcia, E. J., De Alencar, S. M., Reis, A., Loguercio, A. D., Helena, R., \& Grande, M. (2012). Antioxidant Activity by DPPH Assay of Potential Solutions to be Applied on Bleached Teeth. Braz Dent J, 23, 22-27. https:// DOI: 10.1590/S0103-64402012000100004.

Goh, W. N., Rosma, A., Kaur B., Fazilah, A., Karim, A. A., \& Bhat, R. (2012). Fermentation of black tea broth (kombucha): I. effects of sucrose concentration and fermentation time on the yield of microbial cellulose. Int Food Res J, 19, 109-117. https://www.researchgate.net/publication/286302669.

Gopal, J., Muthu, M., Paul, D., Kim, D.-H., \& Chun, S. (2016). Bactericidal activity of green tea extracts: the importance of catechin containing nano particles. Sci Rep, 6. https://doi:10.1038/SREP19710.

Gramza-Michałowska, A., Kulczyński, B., Xindi, Y., \& Gumienna, M. (2016) Research on the effect of culture time on the kombucha tea beverage's antiradical capacity and sensory value. Acta Sci. Pol. Technol. Aliment., 15(4), 447-457. https://doi.org/10.17306/J.AFS.2016.4.43.

Greenwalt, C. j., Ledford, R. A., \& Steinkraus, K. H. (1998). Determination and characterization of the antimicrobial activity of the fermented tea Kombucha LWT. Food Science and Technology, 31(3), 291-296. https://doi.org/10.1006/fstl.1997.0354

Hobbs, C. (1995). Kombucha: Tea Mushroom: The Essential Guide, p. 47-56 Santa Cruz, CA: Botanica Press. https://trove.nla.gov.au/version/45800487

Jarrell, J., Cal, T., \& Bennett, J. W. (2000). The kombucha consortia of yeasts and bacteria. Mycologist, 14, 166-70. https://www.amazon.com/KombuchaManchurian-Essential-Christopher-1995

Jayabalan, R., Malbaša, R. V., Lončar, E. S., Vitas, J. S., \& Sathishkumar, M. (2014). A Review on Kombucha Tea-Microbiology, Composition, Fermentation, Beneficial Effects, Toxicity, and Tea Fungus. Compr Rev Food Sci F, 13, 538 550. https://doi:10.1111/1541-4337.12073.

Jayabalan, R., Malbaša, R. V., \& Sathishkumar, M. (2017). Kombucha Tea: Metabolites. Springer International Publishing, Cham.

Jayabalan, R., Marimuthu, S., \& Swaminathan, K. (2007). Changes in content of organic acids and tea polyphenols during kombucha tea fermentation. Food Chem, 102, 392-398. https://doi:10.1016/j.foodchem.2006.05.032.

Jayabalan, R., Subathradevi, P., Marimuthu, S., Sathishkumar, M., \& Swaminathan, K. (2008). Changes in free-radical scavenging ability of kombucha tea during fermentation. Food Chem, 109, 227-234 https://doi:10.1016/j.foodchem.2007.12.037

Kapp, J. M., \& Sumner, W. 2019. Kombucha: a systematic review of the empirical evidence of human health benefit. Ann Epidemiol, 30, 66-70 https://doi:10.1016/J.ANNEPIDEM.2018.11.001.

Kolár, M., Urbánek, K., \& Látal, T. (2001). Antibiotic selective pressure and development of bacterial resistance. Inter $\mathrm{j}$ antimicrob agents, 17, 357-63. https://DOI: 10.1016/S0924-8579(01)00317

Lee, M.T., Lin, W.C., Yu, B., \& Lee, T.T. (2017). Antioxidant capacity of phytochemicals and their potential effects on oxidative status in animals - A review. Asian-Australas J Anim Sci, 30, 299-308 https://doi:10.5713/ajas.16.0438

Loncar, E., Djuric, M., Malbasa, R., Kolarov, L. J., \& Klasnja, M. (2006) Influence of working conditions upon Kombucha conducted fermentation of black tea. Food and Bioproducts Processing, 84(3), 186-192. https://doi.org/10.1205/fbp.04306

Malbaša, R. V., Lončar, E. S., Vitas, J. S., \& Canadanović-Brunet, J. M. (2011). Influence of starter cultures on the antioxidant activity of kombucha beverage Food Chem,127, 1727-1731. https://doi:10.1016/J.FOODCHEM.2011.02.048.

Malbasa, R. V. (2004). Investigation of antioxidant activity of beverage from tea fungus fermentation

Ph.D.

thesis (in Serbian). University of Novi Sad, Faculty of Technolo gy,NoviSad Martínez Leal,

J., Valenzuela S. L., Jayabalan, R., Huerta Oros, J., \& Escalante-Aburto A (2018). A review on health benefits of kombucha nutritional compounds and $\begin{array}{llll}\text { metabolites. } & \text { Cyta-J } & \text { Food, } & 16,390\end{array}$ 399.https://doi:10.1080/19476337.2017.1410499. May,

A., Narayanan, S., Alcock, J., Varsani, A., Maley, C., \& Aktipis, A. (2019) Kombucha: a novel model system for cooperation and conflict in a complex multi-species microbial 7,e7565.https://doi.org/10.7717/peerj.7565

Mo, H., Zhu, Y., \& Chen, Z. (2008). Microbial fermented tea -A potential source of natural food preservatives. Trends Food Sci. Technol., 19,124 130.https://doi.org/10.1016/j.tifs.2007.10.001

Muhialdin, B. J., Osman, F. A., Muhamad, R., Che Wan Sapawi, C. W. N. S. Anzian, A., Voon, W.W.Y. \& Meor Hussin, A. S. (2019). Effects of sugar sources and fermentation time on the properties of tea fungus (kombucha) beverage, International Food Research Journal, 26(2),481487.http://www.ifrj.upm.edu.my

Naseer, S., Hussain, S., Naeem, N., Pervaiz, M., \& Rahman, M. (2018). The phytochemistry and medicinal value of Psidium guajava (guava).Clin.phytosci,4,32.https://doi:10.1186/s40816-018-0093-8.
Nguyen, N. K., Dong, N.T. N., Nguyen, H.T., \& Le, P. H. (2015). Lactic acid bacteria: promising supplements for enhancing the biological activities of kombucha. SpringerPlus 4, 91.https://doi:10.1186/S40064-015-0872-3. Nuria Elizabeth, Rocha-Guzmán, Martha Rocío Moreno-Jiménez, R.-Q. José Guadalupe, D.M.-N. Juan Antonio, R.-C., \& José Alberto Gallegos-Infante R.F.G.-L. (2018). Polyphenolic Profile, Sugar Consumption and Organic Acids Generation along Fermentation of Infusions from Guava (Pisidium guajava) by the Kombucha Consortium. Recent res. sci. technol, 16-22. https://doi:10.25081/rrst.2018.10.3399. Ochanda, S.O., Kiptoo, Faraj, A., Wanyoko, J. K., Akoth Onyango, C., \& Kipngeno Ruto, H. (2015). Extraction and Quantification of Total Polyphenol Content in Different Parts of Selected Tea Cultivars. Am J Plant Sci, 6, 1581-1586 https://doi:10.4236/ajps.2015.69158.

Pandey, K. B., \& Rizvi, S. I. (2009). Plant polyphenols as dietary antioxidants in human health and disease. Oxid Med Cell Longev, 2, 270-8 https://doi:10.4161/oxim.2.5.9498.

Papuc, C., Goran, G. V., Predescu C.N., Nicorescu, V., \& Stefan, G. (2017) Plant Polyphenols as Antioxidant and Antibacterial Agents for Shelf-Life Extension of Meat and Meat Products: Classification, Structures, Sources, and Action Mechanisms. Compr Rev Food Sci F, 16, 1243-1268. https://doi:10.1111/1541-4337.12298.

Penchovsky, R., \& Traykovska, M. (2015). Designing drugs that overcome antibacterial resistance: where do we stand and what should we do? Expert Opin Drug Discov, 10, 631-650. https://doi:10.1517/17460441.2015.1048219.

Sai Ram, M., Anju B., Pauline T., Dipti P., Kain A. K., Mongia S. S., Sharma, S. K., Singh, B., Singh R., Ilavazhagan G., Kumar, D., \& Selvamurthy, W. (2000) Effect of Kombucha tea on chromate (VI)-induced oxidative stress in albino rats. J Ethnopharmacol, 71, 235-40.

Sajilata, M. G., Bajaj, P. R., \& Singhal, R. S. (2008). Tea Polyphenols as Nutraceuticals. Compr Rev Food Sci F, 7, 229-254. https://doi:10.1111/j.15414337.2008.00043

Sánchez, C. (2017). Reactive oxygen species and antioxidant properties from mushrooms. Syst Synth Biol., 2, 13-22. https://doi:10.1016/j.synbio.2016.12.001. SB, S., \& R. L. (2011). Fermentative Behavior of Saccharomyces Strains During Guava (Psidium Guajava L) Must Fermentation and Optimization of Guava Wine Production. J Food Process Technol, 2, 1-10. https://doi:10.4172/21577110.1000118 .

Scalbert, A., Manach, C., Morand, C., Rémésy, C., \& Jiménez, L. (2005) Dietary Polyphenols and the Prevention of Diseases. Crit Rev Food Sci Nutr, 45 287-306. https:// doi:10.1080/1040869059096.

Shahbazi, H., Hashemi Gahruie, H., Golmakani, M.-T., Eskandari, M. H., \& Movahedi, M. (2018). Effect of medicinal plant type and concentration on physicochemical, antioxidant, antimicrobial, and sensorial properties of kombucha. Food Sci Nutr, 6, 2568-2577. https://doi:10.1002/fsn3.873.

Sharma, O. P., \& Bhat, T. K., (2009). DPPH antioxidant assay revisited. Food Chemistry, 113, 1202-1205. https://doi.org/10.1016/j.foodchem.2008.08.008 Sinir, G. Ö., Tamer, C. E., \& Suna, S. (2019). Kombucha Tea: A Promising Fermented Functional Beverage. Elsevier. https://doi.org/10.1016/B978-0-12 815271-3.00010-5

Sreeramulu, G., Zhu, Y., \& Knol, W. (2000a). Kombucha Fermentation and Its Antimicrobial Activity. J Agric Food Chem, 48, 2589-2594. https://doi:10.1021/jf991333m.

Sreeramulu, G., Zhu, Y., \& Knol, W. (2001a). Characterization Of Antimicrobial Activity In Kombucha Fermentation. Acta Biotechnol, 21, 49-56 Https://Doi:10.1002/1521-3846(200102)21

Steinkraus, K. H., Shapiro, K. B., Hotchkiss, J. H., \& Mortlock (1996) Investigations into the antibiotic activity of tea fungus/kombucha beverage. Acta Biotechnol, 16, 199-205. https://doi:10.1002/abio.370160219.

Stewart, G. F., Schweigert, B. S., Hawthorn John., \& Christopher J., Bauernfeind (1981). Carotenoids as Colorants and Vitamin A Precursors: Technological and Nutritional Applications. Edited by J Christopher Bauernfeind. Academic Press, INC. New York.

Velićanski, A., Cvetković, D., \& Markov, S. (2013). Characteristics of kombucha fermentation on medicinal herbs from lamiaceae family. Rom Biotech Lett, 18 , 8034-8042.

Vīna, I., Semjonovs, P., Linde, R., \& Deniņa, I. (2014). Current evidence on physiological activity and expected health effects of Kombucha fermented beverage. Journal of Medicinal Food, 17, 179-188 https://doi.org/10.1089/jmf.2013.0031

Watawana, M. I., Jayawardena, N., Gunawardhana, C.mB., \& Waisundara V.Y. (2015). Health, Wellness, and Safety Aspects of the Consumption of Kombucha J. of Chem, 1-11. https://doi:10.1155/2015/591869.

Wolfe, B. E., \& Dutton, R. J. (2015). Fermented Foods as Experimentally Tractable Microbial Ecosystems. Cell, 161, 49-55. https://doi.org/10.1016/j.cell.2015.02.034

Yang, L., Ji B-P, Zhou, F., Yang, \& Z-W, Li T. (2008). Study on fermentation conditions of Kombucha key functional bacteria. Food Science, 6, 29.

Zubaidah, Elok, \& Suhardini, P. N. (2016). Studi aktivitas antioksidan Kombucha dari berbagai jenis daun selama fermentasi. J. Pangan dan Agro Industri, 4,1 221-229. 